\title{
Choice between schedules of reinforcement with and without response-pacing requirements
}

\author{
Leigh Schrimpf \\ West Virginia University
}

Follow this and additional works at: https://researchrepository.wvu.edu/etd

\section{Recommended Citation}

Schrimpf, Leigh, "Choice between schedules of reinforcement with and without response-pacing requirements" (2009). Graduate Theses, Dissertations, and Problem Reports. 4528.

https://researchrepository.wvu.edu/etd/4528

This Thesis is protected by copyright and/or related rights. It has been brought to you by the The Research Repository @ WVU with permission from the rights-holder(s). You are free to use this Thesis in any way that is permitted by the copyright and related rights legislation that applies to your use. For other uses you must obtain permission from the rights-holder(s) directly, unless additional rights are indicated by a Creative Commons license in the record and/ or on the work itself. This Thesis has been accepted for inclusion in WVU Graduate Theses, Dissertations, and Problem Reports collection by an authorized administrator of The Research Repository @ WVU. For more information, please contact researchrepository@mail.wvu.edu. 
Choice Between Schedules of Reinforcement With and Without Response-Pacing Requirements

$$
\text { Leigh Schrimpf }
$$

\author{
Thesis submitted to the Eberly College of Arts and Sciences at West Virginia University \\ in Partial Fulfillment of the Requirement for the Degree of \\ Master of Science \\ in \\ Psychology
}

\author{
Michael Perone, Ph.D., Chair \\ Karen G. Anderson, Ph.D. \\ Kevin Larkin, Ph.D. \\ Department of Psychology
}

Morgantown, West Virginia

2009

Keywords: Response Pacing, Value, Concurrent-Chains, Choice, Pigeons 


\begin{abstract}
Choice Between Schedules of Reinforcement With and Without Response-Pacing Requirements Leigh Schrimpf

Differential-reinforcement-of-low-rate (DRL) and differential-reinforcement-of-high-rate (DRH) schedules specify a certain pace of responding eligible for reinforcement. The present study assessed the value of a paced schedule of reinforcement using a concurrent-chains schedule. Pigeon's pecks on the left and right initial-link keys led to one of two terminal-link VI 60-s schedules, programmed on the center key. Completion of a terminal-link schedule always led to access to grain. The value of a terminal-link schedule was measured by the initial-link choice proportions. In the baseline, pecks on either initial-link key produced access to one of two unpaced terminal-link schedules every $60 \mathrm{~s}$, on average. In subsequent experimental conditions, a paced and unpaced terminal-link was available. In the paced conditions restrictions were placed on interresponse times (IRTs) that would be eligible for reinforcement. These restrictions were based on a percentile of baseline IRT distribution. For the DRH conditions, IRTs had to be shorter than the $25^{\text {th }}$ percentile of the distribution and for the DRL conditions IRTs had to be longer than the $75^{\text {th }}$ percentile of the distribution. These durations were adjusted using a changing criterion design. Pacing contingencies had effects on initial and terminal link behavior. Terminal-link response rates were raised above baseline rates in the DRH conditions, and were lowered below baseline rates in the DRL conditions. Three of four pigeons showed an increase in choice for the unpaced schedule when compared to baseline, indicating an increase in value for the unpaced schedules. An analysis of the reinforcement and choice ratios indicate that these differences in value were not due to differences in reinforcement rate.
\end{abstract}




\section{Acknowledgements}

I would like to thank Mike Perone, Karen Anderson, and Kevin Larkin for their helpful suggestions as members of my thesis committee. I would especially like to thank Mike Perone for serving as my chair and advisor. Without his guidance, instruction and humor this project would not be possible.

I would like to thank Anne Foreman for her friendship, her invaluable help with this project, programming and graduate school, and life in general. I also would like to thank Carlos Cançado and Andrew Lightner for their valued friendship and support. Katey, Katherine, Kelly and Heather thank you for always being there. I thank my mother and father for their constant love and encouragement. Lastly, I thank both of my brothers whose hard work and tenacity are always an inspiration to me. 
Table of Contents

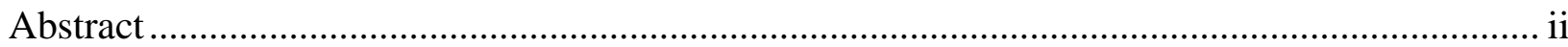

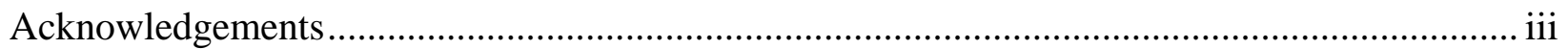

Table of Contents ........................................................................................................ iv

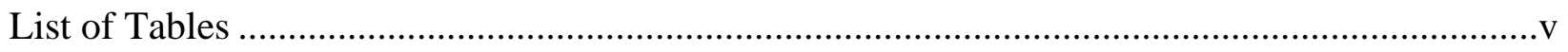

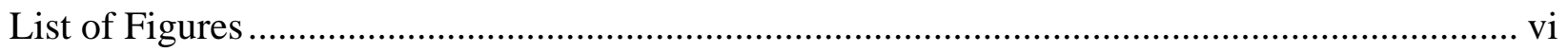

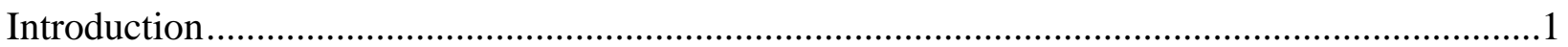

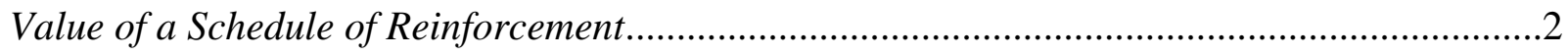

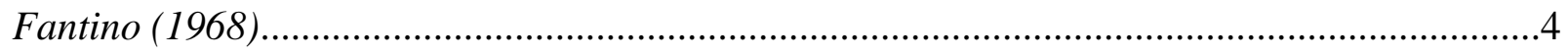

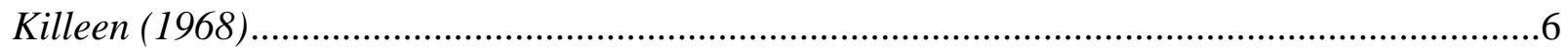

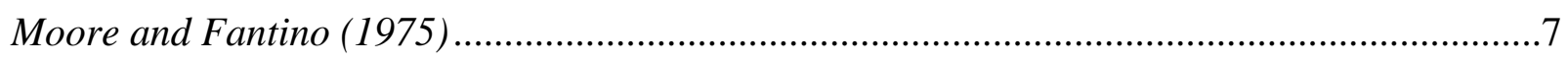

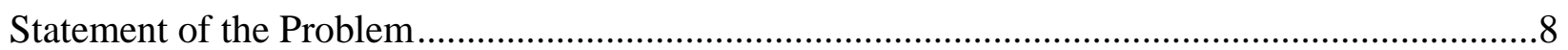

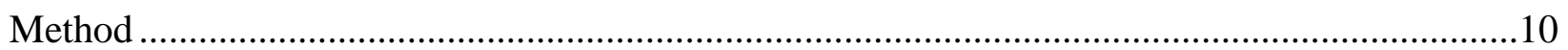

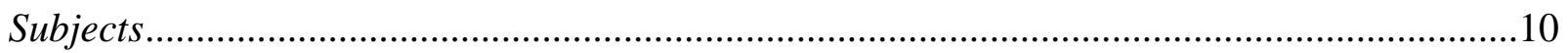

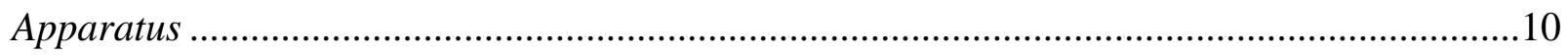

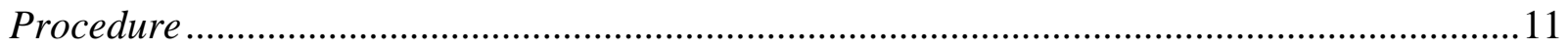

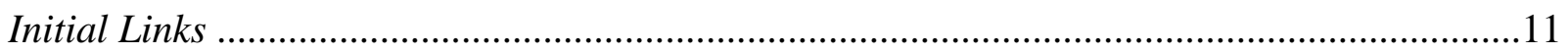

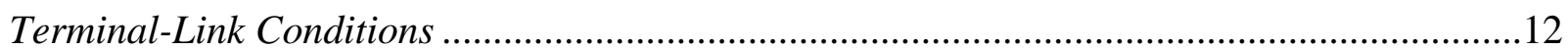

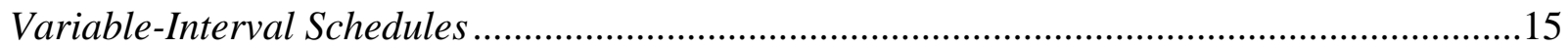

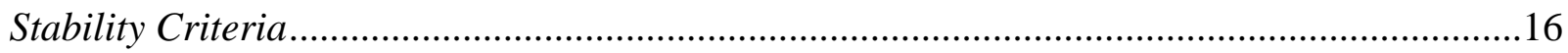

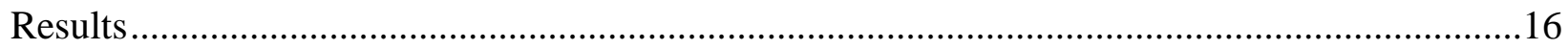

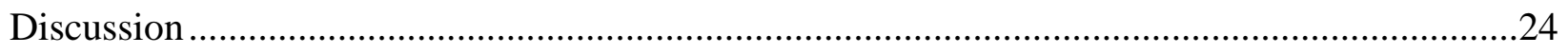

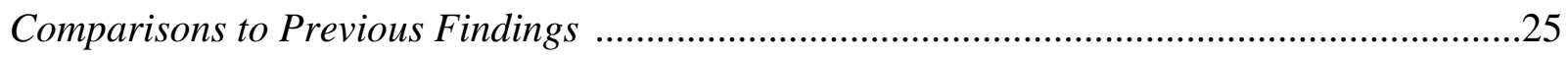

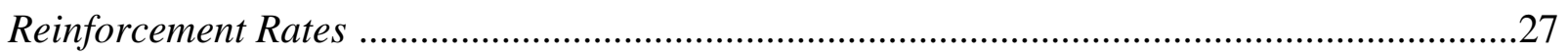

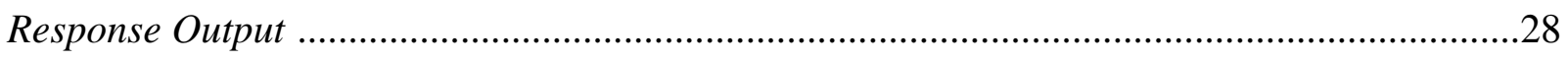

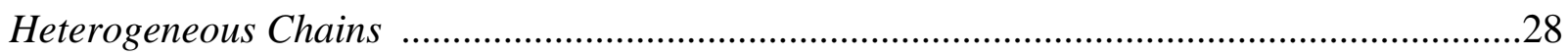

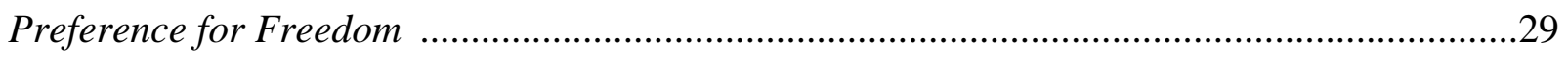

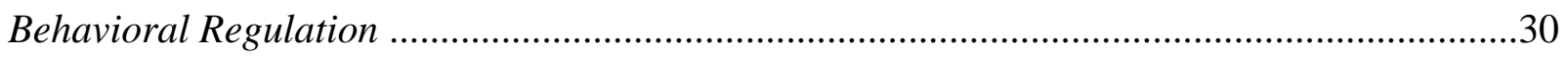

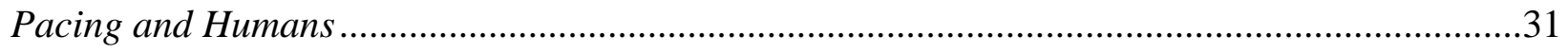

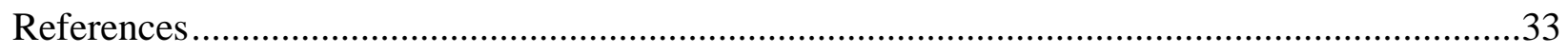




\section{List of Tables}

Table 1. Experimental conditions, the initial-link key leading to the paced terminal link, the interresponse times (IRTs) eligible for reinforcement and the number of sessions per condition for each pigeon.................................................................

Table 2. Experimental conditions, initial-link key leading to the paced terminal link, the initiallink choice proportion, the initial-link response rates for the left and right keys, the response rate for the paced and unpaced terminal links, and the reinforcement rates for the paced and unpaced

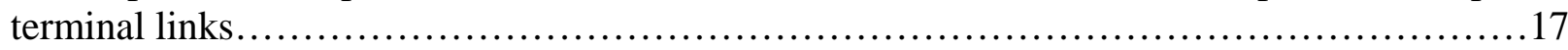




\section{List of Figures}

Figure 1. Response rates for paced and unpaced terminal links during the last 12 sessions of each condition for each pigeon............................................................ 18

Figure 2. Mean choice proportion (plus one standard deviation) during the last 12 sessions of

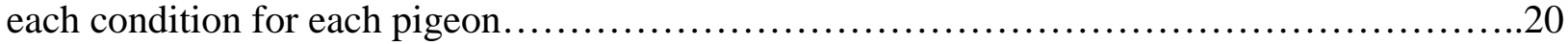

Figure 3. Mean food reinforcement rate (plus one standard deviation) for the paced and unpaced terminal links during the last 12 sessions of each condition for each pigeon...................22

Figure 4. Choice ratio as a function of terminal-link reinforcement ratio for the last 12 sessions of each condition for each pigeon..................................................23 
Introduction

In operant research, a schedule of reinforcement describes the relation among environmental stimuli, a behavior, and a reinforcing consequence such as a food pellet that maintains the behavior. A ratio schedule specifies the number of responses required for reinforcement. An interval schedule specifies an amount of time that must elapse before a response is reinforced. These requirements can remain fixed (fixed-ratio and fixed-interval schedules), or they can vary around an average value (variable-ratio and variable-interval schedules). Ferster and Skinner (1957) explored many different schedules and the various rates and patterns of responding they produce. Variable-ratio (VR) schedules typically produce high, steady rates of responding. Fixed-ratio (FR) schedules usually produce high-rate bursts of responding followed by a pause. Variable-interval (VI) schedules tend to produce steady, moderate rates of responding. Fixed-interval (FI) schedules tend to produce lower rates of responding with a rapid acceleration of responding at the end of the interval.

Although particular rates and patterns are engendered by common schedules, no particular rate or pattern is required by the schedules for reinforcement. It is possible, however, to arrange schedules that do require such dimensions of behavior. This process is called differential reinforcement, and it involves procedures that make specific properties eligible for reinforcement and other response properties ineligible. Of present interest is differential reinforcement of a specific rate or pace of responding. Differential-reinforcement-of-low-rate (DRL) schedules and differential-reinforcement-of-high-rate (DRH) schedules are examples of such pacing contingencies.

Paced responding is required in a variety of everyday settings. Often it is not just the occurrence or nonoccurrence of behavior that is important, but the appropriate pace that makes a 
behavior adaptive. Many manufacturing jobs require employees to work at a pace out of their direct control. Research in the occupational health field suggests that the amount of control that a worker has over his or her work pace relates to levels of personal satisfaction (Shouksmith, 1990). Wergeland and Strand (1998) showed that women with the power to control their own work pace had better pregnancy health than those that did not have such control. Time constraints, and the higher rates of responding they require, have been associated with test anxiety and poor performance in academic settings as well (e.g., Onwuegbuzie \& Seaman, 1995).

There may be a natural pace at which an organism would respond if no temporal constraints were placed on it. Premack (1962) explored the ability of a preferred behavior to serve as a reinforcer for a less preferred behavior. He did this by allowing rats free access to wheel running and drinking water. Baseline rates of wheel running and drinking water were taken and can be considered the natural pace for those behaviors. After baseline, access to the preferred behavior was restricted and made contingent on the occurrence of the less preferred behavior. The occurrence of the less preferred behavior increased under this contingency. The important thing to note from this experiment is that the restricted access to the preferred behavior altered the rate of the alternative behavior and possibly its value.

\section{Value of a Schedule of Reinforcement}

The delivery of individual reinforcers can have different effects based on the context they are delivered in. Factors like delay to reinforcement, magnitude of the reinforcer and the organism's deprivation level can all play a part of in the effectiveness of a reinforcer (Lattal, 1991). Just as primary reinforcers can have different value, conditioned reinforcers can also have different value. The value access to a particular schedule of reinforcement can vary and is 
expressed by how often that schedule is chosen. For example, a schedule that provides a higher rate of reinforcement would be more valuable, and hence preferred, than a schedule that provides a lower rate of reinforcement. Other factors like delay to reinforcement can affect choice, and there are several quantitative models that have different underlying assumptions about what determines the reinforcing value of a schedule (Preston \& Fantino, 1991).

Of present interest is the effect that pacing has on the value of a schedule. A chain schedule is one way to measure this value. Responding in the first part of the chain (the initial link) leads to the second part of the chain (the terminal link). Responding in the initial link is reinforced by access to a terminal-link schedule and responding in the terminal link is reinforced by a primary reinforcer (food delivery). Separating the initial and terminal links allow choice to be measured independent of the schedule requirements in the terminal link.

Thomas (2007) used a chain schedule to assess the effects of pacing contingencies on the value of a VI schedule. Rats’ presses on one lever completed a VI 30-s schedule in the initial link and led to the terminal-link schedule on another lever. The operative lever was signaled by a cue light above it. In the baseline condition, the terminal link consisted of an unpaced VI 30-s schedule leading to a food pellet. In experimental conditions, a pacing contingency was superimposed on the terminal-link VI schedule.

In the DRH condition, only interresponse times (IRTs) less than some duration, $t$, were reinforced (i.e., an IRT $<t$ contingency was added to the terminal-link VI). The initial $t$ value was based on the IRT distribution in the terminal link of the last session of the unpaced baseline. The $t$ duration was set to the $80^{\text {th }}$ percentile of the distribution. After 3 sessions, $t$ was reset to the $80^{\text {th }}$ percentile of the new IRT distribution. This procedure was repeated every 3 sessions until $t$ was unchanged for 3 blocks of 3 sessions. In the DRL condition, a similar procedure was used, 
however, IRTs had to be greater than the $75^{\text {th }}$ percentile of the baseline distribution (an IRT $>t$ contingency).

Response rates in the terminal link increased during the DRH condition and decreased in the DRL condition relative to baseline rates. Despite substantial changes in the terminal-link response rates, there was little change in the initial-link rate across the conditions. This means that although the pacing contingencies had an effect on the rate of terminal-link responding, they had no measurable effect on the value of the terminal-link schedule. Two conclusions are possible: Either these pacing contingencies did not affect the value of the VI schedule, or the chain-schedule procedure was not sufficiently sensitive to detect the effects.

Three published studies concerning the effects of pacing on schedule value used concurrent-chains schedules rather than simple chain schedules. On a concurrent-chains schedule, the subject has two initial-link schedules available concurrently, each leading to a different terminal link. As with simple chains, each terminal-link schedule is regarded as the reinforcer for responding in the corresponding initial link. If one terminal-link schedule has a greater value than the other, response rates in its corresponding initial link should be higher. So, instead of the value of the terminal-link schedules being compared across conditions, the schedules are simultaneously available and value is measured in terms of choice between the schedules. All three studies used pigeons as subjects, key pecking as the response, colored lights projected on the response keys as the discriminative stimuli, and equal VI schedules in the concurrent initial links.

Fantino (1968)

Fantino (1968) arranged requirements for low rates and high rates of responding using pacing contingencies. Initial-link schedules were both VI 60-s and terminal-link schedules were 
either a conventional FI 15-s schedule or a modified FI schedule with a pacing requirement. Across conditions, responding in one initial link led to a paced terminal link in which responding was reinforced on either a DRL or DRH schedule. Responding in the other initial link led to a terminal link in which responding was reinforced on an unpaced schedule.

The DRH schedule required that at least some minimum number of responses be made within $15 \mathrm{~s}$ of the onset of the terminal link. If this requirement was met, the first response after the $15 \mathrm{~s}$ had elapsed was reinforced. The required number of responses varied from pigeon to pigeon, with a range of 5 to 40 and a median of about 25.

The DRL schedule specified the maximum number of responses that could occur within $15 \mathrm{~s}$. If this requirement was met, the first response after $15 \mathrm{~s}$ was reinforced. The maximum number varied across pigeons from 1 to 20 and had a median of about 10 . If either requirement was not met, a reinforcer was not delivered and the initial links were reinstated.

The unpaced terminal-link schedule was a modified fixed-interval (FI) schedule, in which the reinforcement rate was equated to the reinforcement rate in the paced schedule. The duration of the FI was modified so that for each pigeon, the number of programmed reinforcers in the FI for a session was set equal to the number of reinforcers obtained on the paced schedule in the previous session.

Fantino (1968) was able to produce high terminal-link response rates in the DRH condition but he was not able to consistently produce low rates in the DRL. Only one pigeon responded at a lower rate in the DRL than the FI. Considering just the pigeons that came under control of the pacing contingencies, primarily the DRH pigeons, responding occurred at a higher rate in the initial link leading to the unpaced schedule. In other words, the pigeons preferred the unpaced schedule. Although the paced and unpaced terminal links were yoked within a 
condition, there was variability in the obtained reinforcement rates across the different response requirements that were tested. No clear relation was found between percent of trials that resulted in reinforcement and preference, however.

\section{Killeen (1968)}

Killeen (1968) attempted to replicate Fantino’s (1968) study while keeping reinforcement rates constant. In baseline conditions, the pigeon chose between identical VI 30-s terminal links. After each the baseline condition, one of the terminal links had a pacing contingency added to the VI schedule to produce low rates. Responses were only eligible for reinforcement if an average of $30 \mathrm{~s}$ had elapsed and no response had occurred for at least $1.5 \mathrm{~s}$. This schedule was utilized to produce low rates of responding and Killeen referred to it as a DRL schedule. The fact that an absence of responding was reinforced actually made this schedule a differentialreinforcement-of-other-behavior (DRO) schedule.

Response rates differed in the paced and unpaced terminal links. Averaged across birds over the last 5 days of the condition, the unpaced schedule supported rates of about 50 responses per min and the DRL schedule supported rates of about 1 response per min. Despite the effectiveness of the pacing contingency, initial-link choice proportions did not differ from the baseline levels, that is, there was no measureable difference in the value of the schedules.

Killeen (1968) conducted another condition in which the pigeons chose between two unpaced terminal links with different rates of food reinforcement. One terminal link was a VI 30s schedule and the other was a VI 60-s schedule. The pigeons clearly preferred the schedule with the higher rate of reinforcement, showing that the procedure was a sensitive measure of schedule value. The failure to find a change in value by adding the DRO contingency was not due to lack of experimental control. 
Moore and Fantino (1975)

Moore and Fantino (1975) compared terminal links with response-independent schedules and response-dependent schedules. Response-independent schedules deliver a reinforcer regardless of what the animal does, whereas a response-dependent schedule requires a specific behavior. In this sense, a response-dependent schedule is akin to a paced schedule in that it has specific response requirements.

In the first experiment, pigeons chose between a terminal-link schedule that delivered reinforcers independent of responding, on a variable-time (VT) schedule, and a schedule that required responding, on a VI schedule. The VT schedule contained a fixed-time (FT) period, which was adjusted to keep interreinforcement intervals similar in the two schedules. The comparison between these two schedules was made to determine if a required rate per se was responsible for the preference seen by Fantino (1968). If this were the case, the pigeons would be expected to prefer the response-independent VT schedule. These schedules had fewer requirements than the other schedules. The initial-link choice proportion showed near indifference (a proportion of .50) between the two terminal-link schedules. Averaged over the last 9 sessions, the choice proportion for the response-independent schedule was .52 for one pigeon and .46 for the other. These findings conflict with the findings of Fantino's (1968) earlier work, where specific required rates of responding had a negative effect on the schedule value.

In a second experiment, pigeons chose between a response-independent and a responsedependent schedule, but instead of variable intervals of time, they were fixed. The responsedependent schedule was a FI schedule and the response-independent was a FT schedule. The FT schedule was adjusted daily to match the interreinforcer interval of the response-dependent 
terminal-link schedule. Choice proportions in the initial link were above .60 for all pigeons, indicating a preference for the response-independent schedule.

Pigeons were indifferent when choosing between variable schedules but not when choosing between fixed schedules. Moore and Fantino (1975) attempt to reconcile these differences by pointing out that fixed schedules involve a certain degree of predictability, because reinforcement is always set up after the same amount of time. Additional requirements, like pacing contingencies would be difficult to discriminate without that predictability. This is the reason they argue, that the effects of pacing are seen with fixed schedules, but not with variable schedules. This hypothesis certainly is a valid one, but without eliminating some of the procedural problems of the past studies, it is a difficult conclusion to come to with certainty.

\section{Statement of the Problem}

A pacing contingency specifies which rates of behavior are eligible for reinforcement. Requiring a pace of responding different from what the organism would freely emit may affect the value of a schedule of reinforcement. Thomas (2007), Killeen (1968), Fantino (1968), and Moore and Fantino (1975) studied the effect of pacing contingencies on schedule value. Their studies offer conflicting results. Thomas and Killeen found no difference in value between paced and unpaced schedules. Fantino found a preference for unpaced schedules. Moore and Fantino found that required response rates did not affect the value of a schedule if the schedules were variable but did if they were fixed.

The goal of this research was to arrange another test of the effect of pacing on the value of a schedule of reinforcement with refinement in some of the techniques of previous studies. Of the three published studies that analyzed the effects of pacing on value, none reinforced specific IRTs to generate desired response rates. Killeen (1968) used a DRO schedule essentially, in 
which reinforcement was only delivered if an average of $30 \mathrm{~s}$ had elapsed and no response had occurred for at least $1.5 \mathrm{~s}$. Fantino (1968) placed a restriction on the minimum or maximum number of responses in a given amount of time to produce pacing.

These studies did not require a specific IRT terminating at the time of reinforcement. Given these methods of pacing, it would be possible to adventitiously reinforce different length IRTs. Chance reinforcement of short IRTs could be problematic when trying to produce a low rate. Chance reinforcement of longer IRTs could be problematic when trying to produce a high rate. In the current experiment, particular IRTs were reinforced directly following the method devised by Thomas (2007). Not only were the pacing contingencies based on IRTs, but they also were individually determined, that is, each required rate was customized as a percentile of that pigeon’s baseline IRT distribution.

The present study used a concurrent-chains procedure, rather than a simple chains procedure. In the initial link, pecks on either of two side keys occasionally produced access to one of two terminal-link schedules. In the baseline conditions, a simple VI 60-s schedule was programmed in terminal links. In the experimental conditions, one of the terminal links remained unpaced while the other added response pacing to the VI schedule. In the DRL condition, only responses that terminated long IRTs were eligible for reinforcement on the paced VI schedule. In the DRH condition, only responses that terminated short IRTs were eligible. Completing the terminal-link schedule produced a food reinforcer.

First, a baseline condition was performed. In this baseline both terminal-link schedules were unpaced. A percentile of the baseline IRT distribution was used to create the pacing contingency in the next condition. Half of the pigeons were exposed to the DRL conditions and half were exposed to the DRH conditions. The IRT restriction became progressively more 
stringent until responding stabilized. Reversals were conducted after the DRL and DRH conditions to check for a side bias. This experiment aimed to use these refinements in method to provide data so that conclusions about how pacing affects schedule value could be made.

Method

Subjects

Four male White Carneau pigeons, all with experience on a variety of schedules, were maintained at $80 \%(+/-2 \%)$ of their free-feeding weights by grain deliveries during the experimental sessions and, when necessary, by supplemental feedings at least 30 min afterwards. Water and health grit were freely available in the home cage, which was kept in a temperature controlled room with a 12:12 hr light/dark cycle.

Apparatus

Four standard sound-attenuating chambers were used. Each chamber measured $37 \mathrm{~cm}$ high, $30 \mathrm{~cm}$ wide, and $32 \mathrm{~cm}$ deep. General illumination was provided by a 28-v houselight (No. 1819) located behind a translucent screen in the lower left corner of the front panel. Three response keys, about $2 \mathrm{~cm}$ in diameter, were arranged in a row on the front panel $24 \mathrm{~cm}$ from the floor and 9 cm apart, center to center. When operative, keys were illuminated from behind by 28v bulbs (No.1829) covered with colored caps. Food reinforcers consisted of access to mixed grain through an illuminated (No. 1819 bulb) 5-cm x 6-cm rectangular aperture located approximately $11 \mathrm{~cm}$ below the center key. Noise from a ventilation fan on the side of the chamber masked extraneous sounds. Experimental events were controlled and recorded using microcomputers connected to the chambers by a commercial interface. 


\section{Procedure}

The goal of the present experiment was to study choice between paced and unpaced schedules of reinforcement. This was done using a concurrent-chains schedule. In the initial link, the left and right keys were lit blue and pecks occasionally produced access to a terminallink schedule programmed on the center key. If the initial link was completed on the left key, the center key was lit white. If the initial link was completed on the right key, the center key was lit green. The experimental conditions differed in terms of the schedules in the white and green terminal links. In the baseline conditions, a conventional VI 60-s schedule was programmed in both the white and green terminal links. In these unpaced schedules, a response that terminated an IRT of any duration was eligible for reinforcement. In the experimental conditions, one of the terminal links remained unpaced while the other added a response pacing requirement to the VI schedule. In the DRL condition, only responses that terminated long IRTs were eligible for reinforcement on the paced VI schedule. In the DRH condition, only responses that terminated short IRTs were eligible. Completing the terminal-link schedule produced a food reinforcer. Sessions lasted until 40 reinforcers had been delivered. Sessions were run at approximately the same time of day, six days a week.

\section{Initial Links}

Responding in the initial links produced entry into a terminal link by the method described by Stubbs and Pliskoff (1969). A single VI 30-s schedule was arranged. When an interval elapsed, the terminal-link entry was assigned at random to either the left or right key, with the restriction that entry would be assigned to the same key no more than 3 times in succession. With this procedure, pecks on each key led to a terminal link every 60 s on average, and both terminal-link schedules would be entered equally often regardless of the distribution of 
responses. A 2-s changeover specified the minimum amount of time that had to elapse between a switch from one key to another and the presentation of a terminal link.

\section{Terminal-Link Conditions}

Table 1 shows the sequence of experimental conditions.

Baseline. In the initial condition, responding in both terminal links was reinforced with food according to a conventional VI 60-s schedule (details below). After an interval elapsed, a response that terminated an IRT of any duration was reinforced. The baseline condition was continued until responding in both the initial links and terminal links was judged stable by the criteria described below. The distribution of terminal-link IRTs in the last baseline session was used to establish the basis of the pacing parameter used in the subsequent condition.

$D R H$. In the DRH conditions, one of the terminal links contained a conventional VI 60-s schedule and the other contained a paced schedule in which IRTs had to be shorter than some duration $t$ to be eligible for reinforcement (i.e., an IRT $<t$ contingency was superimposed on the VI schedule). In the first part of the DRH condition a changing criterion design was used and $t$ was individualized on the basis of each pigeon's terminal-link IRT distribution. This condition began with $t$ set to the $25^{\text {th }}$ percentile of the IRT distribution during the last baseline session. This $t$ was programmed for a block of 3 sessions. Next, $t$ was reset to the $25^{\text {th }}$ percentile of the IRT distribution of the last session of the block, as long as the new $t$ was more stringent - or shorter -- than the old $t$. If it was not more stringent, $t$ was retained for another block. This procedure was repeated until $t$ was stable for 3 blocks, at which point no further changes were made to $t$. The DRH condition proper began when the terminal $t$ duration was reached. The terminal $t$ duration for each pigeon is listed on Table 1. This condition continued until responding stabilized according to the criteria described below. For pigeon 9911, setting $t$ to the 


\section{Table 1}

Experimental conditions (in the order of occurrence), the initial-link key leading to the paced terminal link, the interresponse times (IRTs) eligible for reinforcement in both the paced and unpaced terminal links, and the number of sessions per condition for each pigeon. Paced conditions arranged either a differential-reinforcement-of-high-rate schedule (DRH) or a differentialreinforcement-of-low-rate schedule (DRL).

\begin{tabular}{|c|c|c|c|c|c|}
\hline \multirow[b]{2}{*}{ Pigeon } & \multirow[b]{2}{*}{ Condition } & \multirow{2}{*}{$\begin{array}{c}\text { Initial Link } \\
\text { Leading to Pacing }\end{array}$} & \multicolumn{2}{|c|}{$\begin{array}{c}\text { Terminal-Link } \\
\text { IRTs (s) Eligible } \\
\text { for Reinforcement }\end{array}$} & \multirow[b]{2}{*}{ Sessions } \\
\hline & & & Unpaced & Paced & \\
\hline \multirow[t]{4}{*}{6893} & Baseline & Right & All & All & 42 \\
\hline & DRH & Right & All & $<0.09$ & 49 \\
\hline & $\mathrm{DRH}$ & Left & All & $<0.09$ & 22 \\
\hline & Baseline & Left & All & All & 23 \\
\hline \multirow[t]{4}{*}{9911} & Baseline & Left & All & All & 49 \\
\hline & DRH & Left & All & $<0.05$ & 87 \\
\hline & DRH & Right & All & $<0.05$ & 41 \\
\hline & Baseline & Right & All & All & 38 \\
\hline \multirow[t]{4}{*}{9922} & Baseline & Left & All & All & 51 \\
\hline & DRL & Left & All & $>1.66$ & 41 \\
\hline & DRL & Right & All & $>1.66$ & 50 \\
\hline & Baseline & Right & All & All & 39 \\
\hline \multirow[t]{4}{*}{6689} & Baseline & Left & All & All & 40 \\
\hline & DRL & Left & All & $>2.57$ & 98 \\
\hline & DRL & Right & All & $>2.57$ & 40 \\
\hline & Baseline & Right & All & All & 21 \\
\hline
\end{tabular}


$25^{\text {th }}$ percentile did not produce differentiation between paced and unpaced terminal-link response rates, so a more stringent criterion, the $10^{\text {th }}$ percentile, was used. In the DRH Reversal condition, the relations between the left and right initial-link keys and the paced and unpaced terminal-link schedules were switched: initial-link responding on the side key that originally led to a paced terminal link now led to an unpaced terminal link, and responding on the side key that originally led to an unpaced terminal link now led to a paced terminal link. The center key colors associated with the terminal-link schedules remained the same.

DRL. In the DRL condition, one of the terminal links contained a conventional VI 60-s schedule and the other contained a paced schedule in which IRTs had to be longer than some duration $t$ to be eligible for reinforcement (i.e., an IRT $>t$ contingency was superimposed on the VI schedule). In the beginning of the DRL condition a changing criterion design was used and $t$ was individualized on the basis of each pigeon's terminal-link IRT distribution. Initially $t$ was set to the $75^{\text {th }}$ percentile of the IRT distribution during the last baseline session. This $t$ was programmed for a block of 3 sessions. Next, $t$ was reset to the $75^{\text {th }}$ percentile of the IRT distribution of the last session of the block, as long as the $t$ was more stringent - or longer -- than the previous $t$. If it was not more stringent, $t$ was retained for another block. This procedure was repeated until $t$ was stable for 3 blocks, at which point no further changes were made to $t$. The DRL condition proper began when the terminal $t$ duration was reached. The terminal $t$ duration for each pigeon is listed on Table 1. This condition continued until responding stabilized. For pigeon 9922, setting $t$ to the $75^{\text {th }}$ percentile did not produce differentiation between paced and unpaced terminal-link response rates, so a more stringent criterion, the $90^{\text {th }}$ percentile, was used. In the DRL Reversal condition, the relations between the left and right initial-link keys and the paced and unpaced terminal-link schedules were switched: initial-link responding on the side key 
that originally led to a paced terminal link now led to an unpaced terminal link, and responding on the side key that originally led to an unpaced terminal link now led to a paced terminal link. The center key colors associated with the terminal-link schedules remained the same.

Order of conditions and terminal-link stimuli. Pigeons 6893 and 9911 were exposed to the DRH conditions and Pigeons 9922 and 6689 were exposed to DRL conditions. The key colors associated with the paced and unpaced terminal links was switched for one bird. For Pigeon 6893 the center key was lit green during the paced terminal link and white during the unpaced terminal link. For Pigeons 9911, 9922, and 6689 the center key was lit white during the paced terminal link and green during the unpaced. The color of the paced terminal link was decided based on the pigeons' baseline responding. In order to provide a conservative test of the effects of pacing, the initial link that was preferred was assigned to lead to terminal-link pacing. This way, if there was a preference for the unpaced terminal link there would be a large change in choice.

\section{Variable-Interval Schedules}

The VI schedules in the initial links and the terminal links consisted of 10 intervals computed according to Fleshler and Hoffman's (1962) formula. For each of the three schedules (initial-link VI 30-s, white terminal-link VI 60-s, green terminal-link VI 60-s), the intervals were drawn at random from the pool of 10, without replacement, until the pool was exhausted, whereupon the pool was be replenished and the process started anew.

During the baseline condition and the first 22 sessions of the first pacing condition for each pigeon, reinforcement rates were affected due to a programming error. Both green and white terminal-links shared the same distribution of VI schedule intervals when they should have been independent. This error caused the reinforcement rates to average out to one reinforcer per 
min over the two terminal links, not within an individual terminal link. This error is reflected in the rates of over one reinforcer per min in the baseline conditions (which are listed in Table 2). The differences in reinforcement rate between the unpaced and paced terminal links were small $(+0.03,-0.07,+0.05,0.00$, respectively) for each pigeon in the baseline condition. This programming error also led to greater variation in the reinforcement rates in the baseline condition which are reflected by the larger standard deviations seen in Table 2 . After the $22^{\text {nd }}$ session of the first pacing condition, this error was corrected.

\section{Stability Criteria}

Each condition lasted a minimum of 20 sessions and until responding in both the initial links and terminal links was judged stable. To assess initial-link responding, the last 12 sessions were split into 4 blocks of 3 sessions each. Responding was judged stable when the mean choice proportions (i.e., the number of responses in the initial link leading to the unpaced terminal link divided by the total number of responses in both initial links) of each block differed by no more than 0.10 and no systematic upward or downward trend was seen in the block means. Separate assessments were made of responding in white and green terminal links. The last 12 sessions were split into 2 blocks of 6 sessions each. Responding was judged stable when the difference between the block means was within $10 \%$ of the mean of all 12 sessions, or when the difference between the block means was within 2 responses per min.

\section{Results}

Table 2 lists mean choice proportions, initial-link response rates, terminal-link response rates, and reinforcement rates of the stable sessions. Figure 1 shows response rates in the paced and unpaced terminal links for the last 12 sessions of each condition. The terminal links are labeled paced and unpaced throughout the figure, for ease of reading, but the Baseline conditions 


\section{Table 2}

Experimental conditions (in the order of occurrence), the initial-link key leading to the paced terminal link, the initial-link choice proportion (calculated by dividing number of responses on the left key by the number of responses on the left and right keys), the initial-link response rates for the left and right keys, the response rates for the paced and unpaced terminal links, and reinforcement rates for the paced and unpaced terminal links. Paced conditions arranged either a differential-reinforcement-of-high-rate (DRH) schedule or a differential-reinforcement-of-low-rate (DRL) schedule. Shown are means of the last 12 sessions of each condition, with standard deviations in parenthesis.

\begin{tabular}{|c|c|c|c|c|c|c|c|c|c|}
\hline \multirow[b]{2}{*}{ Pigeon } & \multirow[b]{2}{*}{ Condition } & \multirow{2}{*}{$\begin{array}{l}\text { Initial } \\
\text { Link that } \\
\text { leads to } \\
\text { Pacing }\end{array}$} & \multirow{2}{*}{$\begin{array}{c}\text { Choice } \\
\text { Proportion } \\
\mathrm{L} /(\mathrm{L}+\mathrm{R}) \\
\end{array}$} & \multicolumn{2}{|c|}{ Initial-Link Responses/Min } & \multicolumn{2}{|c|}{ Terminal-Link Responses/Min } & \multicolumn{2}{|c|}{$\begin{array}{l}\text { Obtained Terminal-Link } \\
\text { Reinforcers/Min }\end{array}$} \\
\hline & & & & Left & Right & Unpaced & Paced & Unpaced & Paced \\
\hline \multirow{3}{*}{6893} & DRH & Right & $0.41(0.02)$ & $28.16(2.54)$ & $41.17(4.55)$ & $79.68(4.60)$ & $130.59(10.26)$ & $0.99(0.00)$ & $0.97(0.01)$ \\
\hline & $\mathrm{DRH}$ & Left & $0.44(0.03)$ & $29.81(2.57)$ & $37.60(4.62)$ & $69.23(9.60)$ & $147.81(15.58)$ & $0.99(0.00)$ & $0.98(0.00)$ \\
\hline & Baseline & Left & $0.43(0.03)$ & $31.91(2.30)$ & $42.61(3.85)$ & $63.92(4.55)$ & $86.91(5.01)$ & $0.99(0.00)$ & $0.99(0.00)$ \\
\hline \multirow[t]{4}{*}{9911} & Baseline & Left & $0.63(0.08)$ & $13.02(2.86)$ & $7.43(1.54)$ & $63.93(4.37)$ & $65.16(7.29)$ & $0.98(0.15)$ & $1.05(0.17)$ \\
\hline & DRH & Left & $0.40(0.05)$ & $10.73(1.88)$ & $16.51(3.24)$ & $76.86(7.27)$ & $98.24(7.05)$ & $0.99(0.00)$ & $0.84(0.06)$ \\
\hline & $\mathrm{DRH}$ & Right & $0.75(0.05)$ & $16.23(2.44)$ & $5.41(1.15)$ & $62.20(6.06)$ & $105.12(7.94)$ & $0.98(0.00)$ & $0.82(0.09)$ \\
\hline & Baseline & Right & $0.60(0.08)$ & 13.59 (2.33) & 9.04 (1.99) & $57.9(5.22)$ & $62.42(3.75)$ & $0.99(0.01)$ & $0.99(0.00)$ \\
\hline 9922 & Baseline & Left & $0.62(0.05)$ & 58.17 (5.37) & 35.46 (5.43) & 119.23 (11.15) & $103.32(6.23)$ & $1.03(0.12)$ & $0.98(0.00)$ \\
\hline \multirow[t]{4}{*}{6689} & Baseline & Left & $0.59(0.02)$ & 44.15 (2.32) & 30.64 (1.70) & $59.11(4.06)$ & 67.41 (6.39) & $1.02(0.21)$ & $1.02(0.17)$ \\
\hline & DRL & Left & $0.31(0.04)$ & 27.02 (3.85) & $59.88(4.16)$ & $55.34(5.20)$ & $23.66(0.99)$ & $0.99(0.00)$ & $0.92(0.02)$ \\
\hline & DRL & Right & $0.48(0.05)$ & 38.98 (4.12) & 43.09 (4.29) & 68.35 (3.07) & $19.11(2.81)$ & $0.99(0.01)$ & $0.95(0.02)$ \\
\hline & Baseline & Right & $0.37(0.03)$ & $38.11(2.45)$ & $66.75(4.75)$ & $65.21(2.24)$ & $36.32(1.88)$ & $0.99(0.00)$ & $0.99(0.00)$ \\
\hline
\end{tabular}




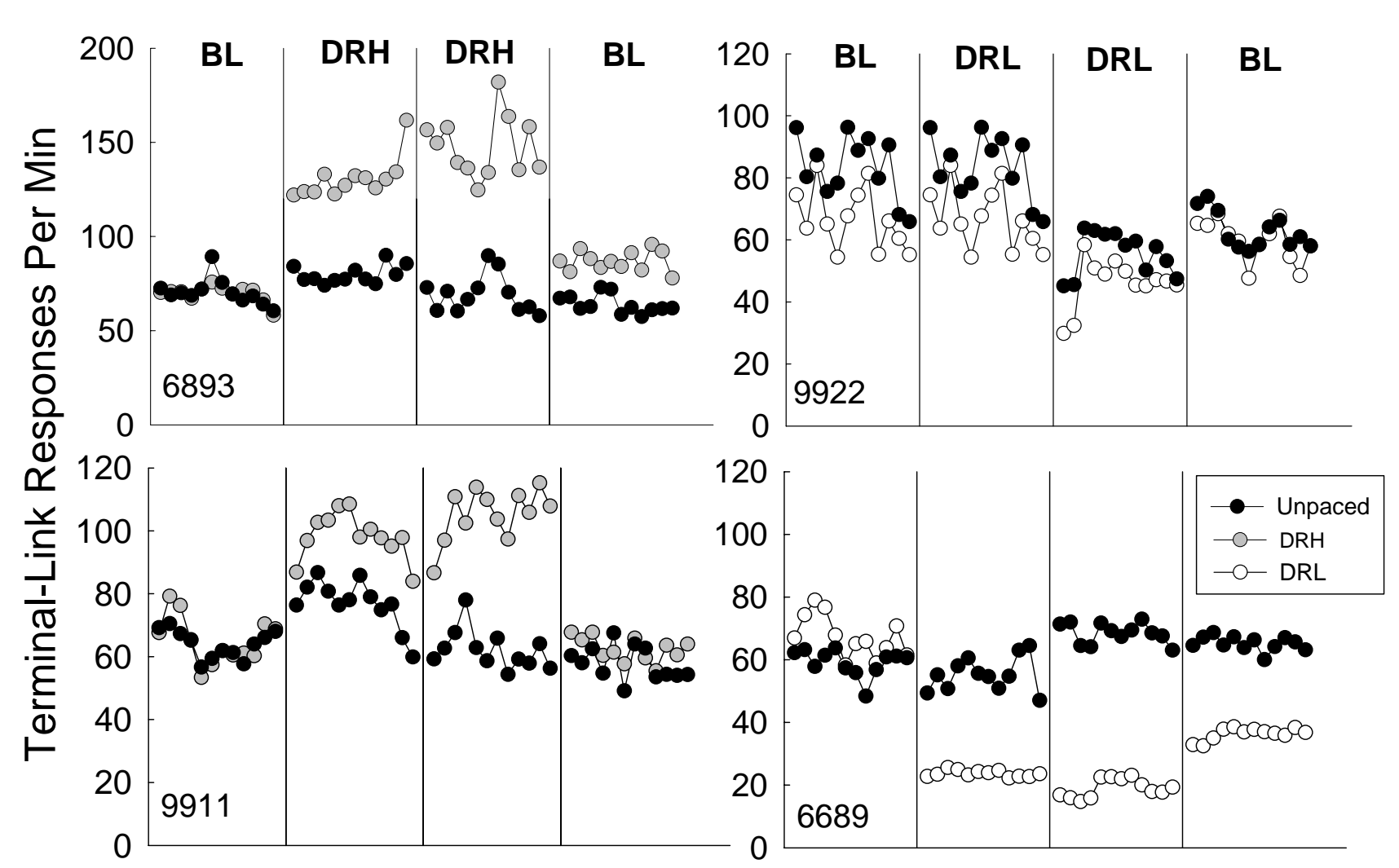

Last 12 Sessions

Figure 1. Response rates for paced and unpaced terminal links during the last 12 sessions of each condition. Paced conditions arranged either a differential-reinforcement-of-high-rate (DRH) schedule or a differential-reinforcement-of-low-rate (DRL) schedule. The second paced condition for each pigeon was an initial-link reversal, in which the initial-link key associated with each terminal-link schedule was switched. Contingencies in the terminal links remained the same during the reversal. Baseline (BL) conditions did not have pacing requirements in either link. Note that the y-axis for Pigeon 6893 is different from the other y-axes. 
did not have pacing requirements in either terminal link. The second paced condition (DRH or DRL) was an initial-link reversal, where the side key that led to each terminal link was switched. Pacing contingencies were generally effective at controlling terminal-link response rates. In the Baseline condition, response rates were similar in both terminal links for most pigeons (the exception was Pigeon 9922). The addition of DRH pacing requirements increased response rates in the paced terminal link, while rates in the unpaced link remained close to Baseline rates. The addition of DRL pacing requirements decreased rates in the paced terminal link for Pigeon 6689, but was not as effective for Pigeon 9922. For this pigeon, response rates in the first DRL condition were similar to Baseline rates in the first experimental condition. Rates did drop in the second experimental condition, but there was little separation between the paced and unpaced response rates. For all pigeons, the Baseline replication was effective at reducing the differences in rates between the paced and unpaced terminal links seen in the experimental conditions.

Figure 2 shows the mean initial-link choice proportion (plus one standard deviation) of the last 12 sessions of each condition. The letters $(\mathrm{L}, \mathrm{R})$ above the bars representing paced conditions indicates which side key, left or right, led to a paced terminal link. The dashed line indicates indifference. Bars above the dashed line represent a preference for the left initial-link key and bars under the dashed line represent a preference for the right.

The pacing contingencies had a clear effect on choice between the terminal links in 3 of 4 pigeons. In Pigeon 9911's first experimental condition, the left initial link led to a paced terminal link with a DRH contingency. Relative to the Baseline condition, choice proportions shifted to the right. During the reversal, when the initial link that led to the DRH terminal link was on the right, choice shifted to the left. Similar results were obtained with Pigeons 9922 and 6689 when DRL requirements were added. When the left initial link led to the paced terminal link, choice 


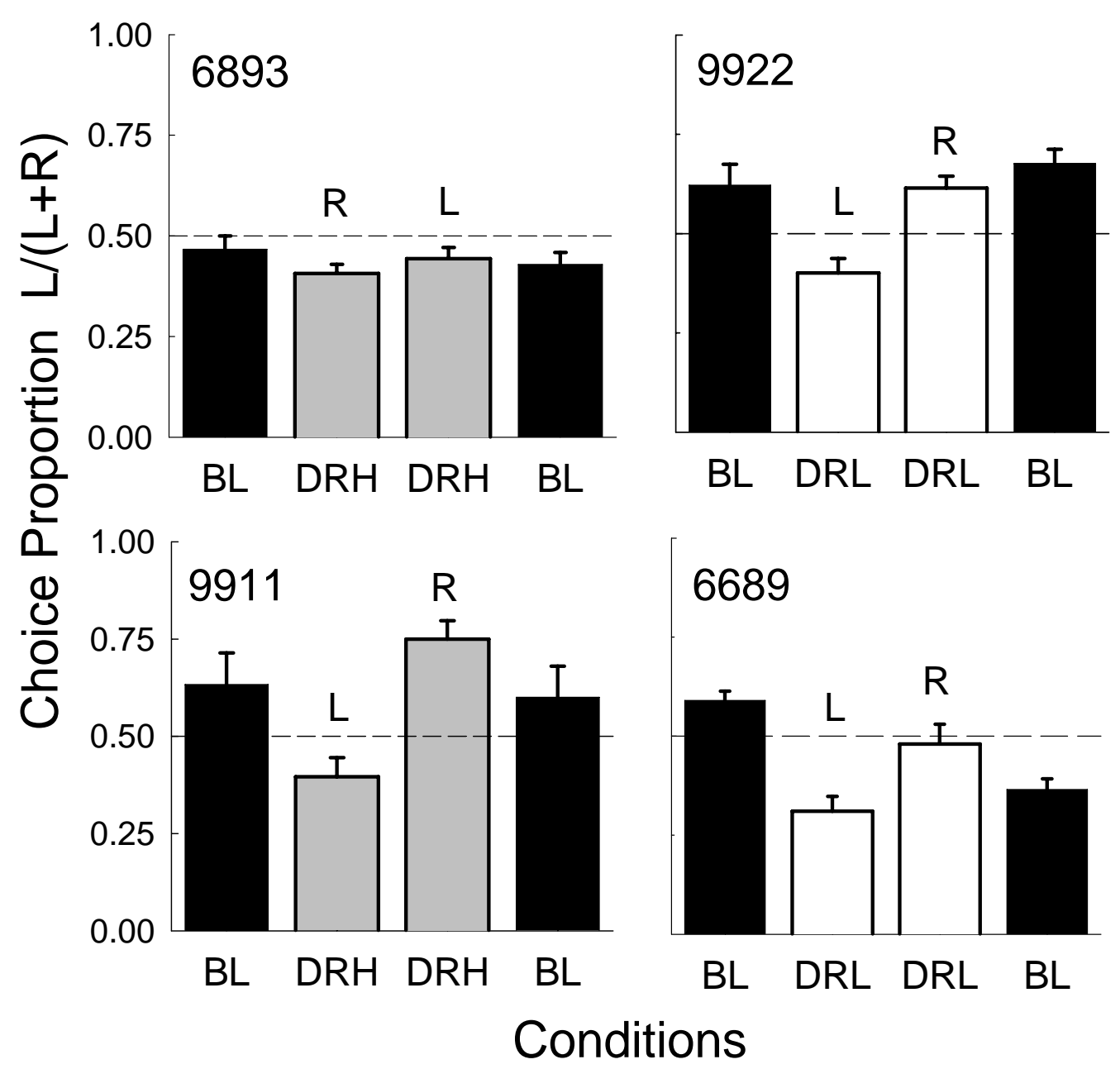

Figure 2. Mean choice proportion (plus one standard deviation) during the last 12 sessions of the Baseline (BL), differential-reinforcement-of-high-rate (DRH) schedule, and differential-reinforcement-of-low-rate (DRL) schedule conditions. The dashed line indicates indifference. The letters $(\mathrm{L}, \mathrm{R})$ above the bars representing paced conditions indicate which side key, left or right, led to a paced terminal link. 
shifted toward the left. In the fourth subject, Pigeon 6893, choice proportions remained near indifference throughout the experiment.

Figure 3 shows the rate of food reinforcement in the paced and unpaced terminal links, averaged over the last 12 sessions of each condition. In the experimental conditions, obtained reinforcement rates dropped below the programmed rate of 1 per min in the paced terminal links. The discrepancies, however, were small. Averaging across all 8 experimental conditions for all pigeons, the reinforcement rate in the paced terminal link was 91 percent of the rate of the unpaced link. For the pairs of experimental conditions experienced by the individual pigeons, the paced terminal-link percentages were 99, 84, 91, and 94 for pigeons 6893, 9911, 9922 and 6689, respectively. Also apparent in Figure 3 is an unusual degree of variability in the reinforcement rates in the first Baseline condition (as shown by the error bars which represent one standard deviation). This is a reflection of the programming error noted in the Method section, not a characteristic of the pigeons’ behavior.

The reduced reinforcement rates in the paced terminal links could be responsible for the pigeons’ preferences for the unpaced terminal links. Indeed, the three pigeons with clear preferences for the unpaced link (Pigeons 9911, 9922, and 6689) are also the pigeons with the largest difference in reinforcement rate favoring the unpaced terminal link.

Figure 4 shows a finer grained analysis of the influence of the terminal-link reinforcement rate on initial-link choice. The figure plots, on a logarithmic scale, the relation between the ratio of initial-link response rates on the side keys leading to unpaced and paced terminal links (choice ratios) and the ratio of the terminal-link reinforcement rates in the paced and unpaced terminal links (reinforcement ratios). Each data point is based on the results from a single stable session; there are a total of 12 points from the first Baseline condition (black 


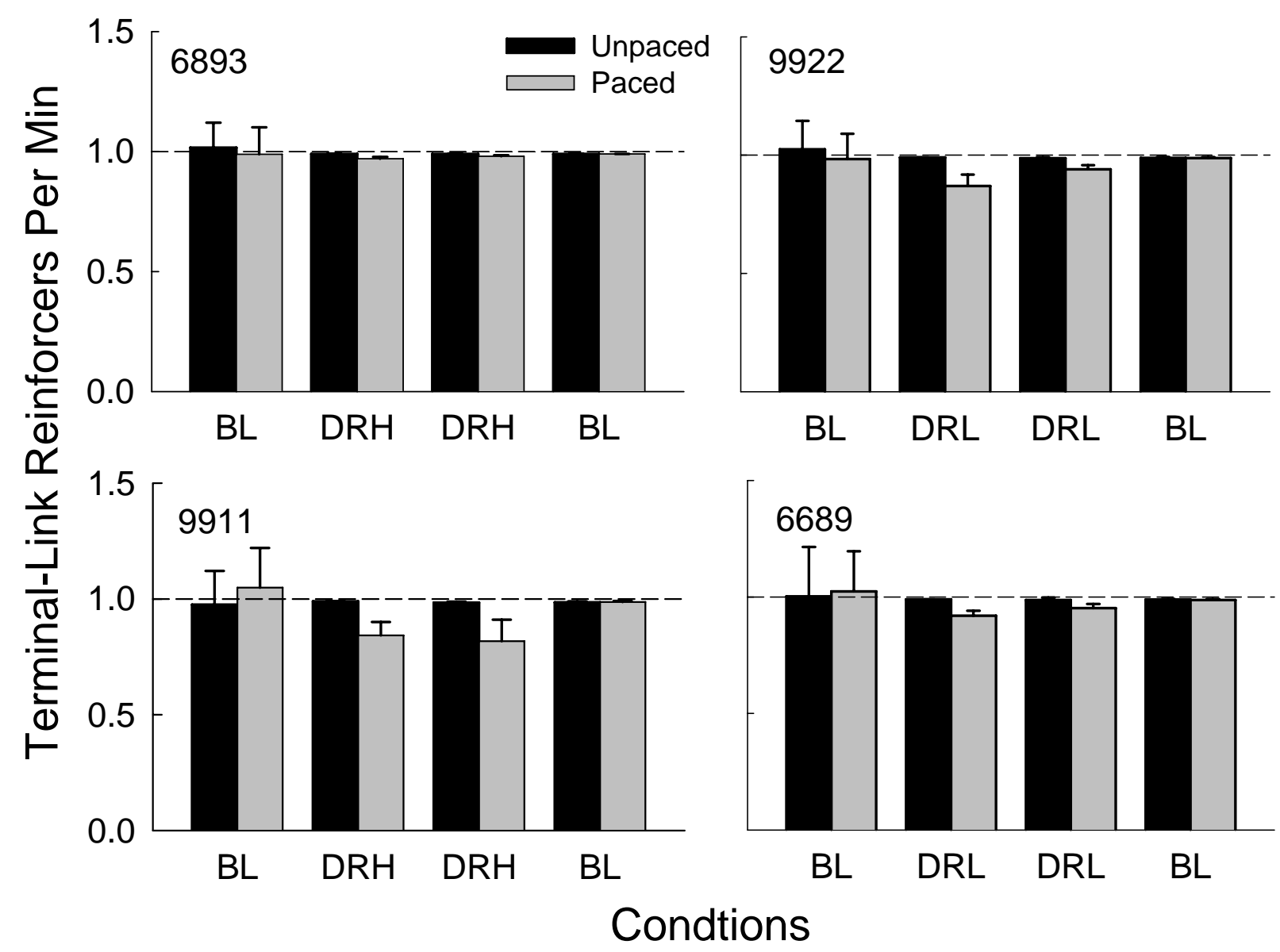

Figure 3. Mean food reinforcement rate (plus one standard deviation) for the paced and unpaced terminal links during the last 12 sessions of the Baseline (BL), differentialreinforcement-of -high-rate (DRH) schedule, and differential-reinforcement-of-low-rate schedule (DRL) conditions. 


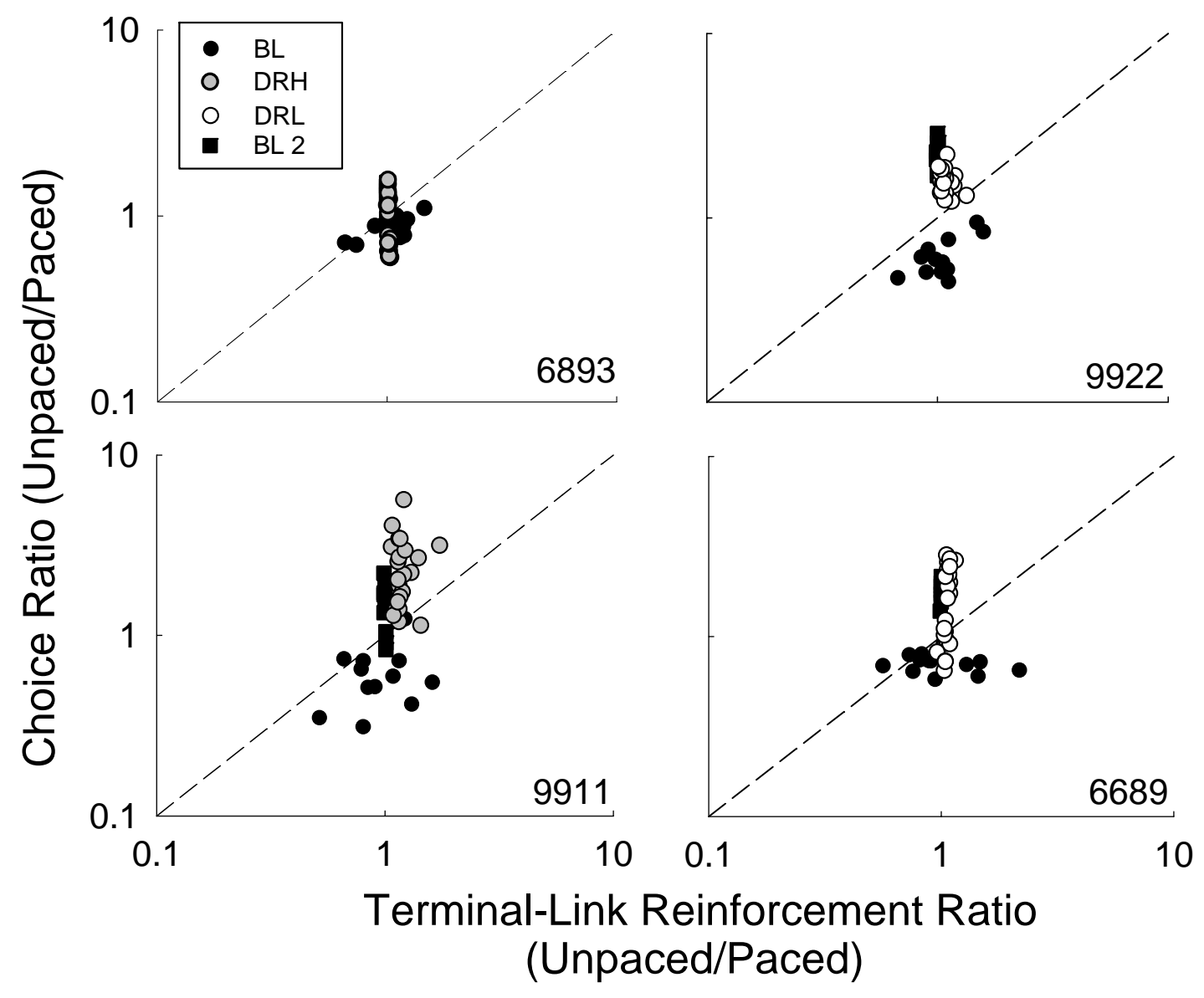

Figure 4. Choice ratio as a function of terminal-link reinforcement ratio for the last 12 sessions of the Baseline (BL), differential-reinforcement-of -high-rate (DRH) schedule, differential-reinforcement-of-low-rate (DRL) schedule conditions, and Baseline replication (BL2). 
circles), 24 points from the paced conditions (gray circles for DRH, white circles for DRL), and 12 points from the second Baseline condition (black squares). If the pigeons’ choice in the initial links matched the rates of food reinforcement in the terminal links, the data would fall along the dashed diagonal line.

Session-to-session variation in choice was unrelated to session-to-session variation in terminal-link reinforcement ratios. Most of the variation in reinforcement rates occurred in the first Baseline condition. This reflects the programming error mentioned above. In the paced conditions, the data points fall in a tight cluster near equality. This shows that, from session to session, the reinforcement rates remained close to the programmed rates in both the paced and unpaced terminal links. Nevertheless there was variability from session to session in the choice ratios. In line with Figure 2, Figure 4 also shows that the session-by-session choice ratios favored the unpaced terminal link in 3 of 4 pigeons (the exception was 6893). Almost all of the choice ratios from the experimental sessions fall above the diagonal.

\section{Discussion}

The present study found clear effects of IRT-based pacing contingencies on behavior in the terminal and initial links. Response rates in the paced terminal links increased under the DRH conditions and decreased under the DRL conditions. Responding in the unpaced terminal links remained fairly stable across conditions for most pigeons. Perhaps because of the individualized, gradual method used to set the pacing requirements, the reinforcement rates in the paced and unpaced terminal links remained close to the programmed rate of one reinforcer per min. During the experimental conditions in which pigeons were given a choice between paced and unpaced terminal links, behavior in the initial link changed from baseline levels. Most pigeons preferred the unpaced terminal link to the paced terminal link. These initial-link choices indicate that the 
unpaced terminal link had a greater reinforcing value than the paced terminal link. The single exception was indifferent.

It is possible for the pacing contingencies to have an effect on the value of a schedule without changing the terminal-link response rates much, or at all, and it is also possible for the value of a schedule to remain the same while the contingencies affect terminal-link behavior. Pigeon 6893 showed marked effects of the DRH pacing contingencies on terminal-link responding, with differences of 50 to 75 responses per min between the paced and unpaced terminal links. These differences in response rate did not produce any significant changes in initial-link choice proportion, however. The opposite was seen with Pigeon 9922. For this pigeon, the differences in response rates between the DRL paced and unpaced terminal-links were relatively small, 10 to 15 responses per min. A clear difference in initial-link choice proportion was seen, however, with this pigeon favoring the unpaced terminal link.

\section{Comparisons to Previous Findings}

Both the present study and Fantino’s (1968) study found effects of pacing on the value of a schedule of reinforcement, while Killeen (1968) found no difference in value between paced and unpaced schedules. What variables can account for these discrepant results? The studies of interest were similar in three main ways. First, pacing contingencies had a clear effect on terminal-link response rates in all of the studies. Second, all studies used VI schedules in the initial links that produced a terminal link every 60 s, on average. Lastly, all three studies attempted to equate the obtained reinforcement rates in the paced and unpaced terminal links.

The studies of interest had three main procedural differences that may account for the discrepancy seen with the effects of pacing on schedule value. First, all three studies used different methods to produce pacing contingencies. Second, the study that found negative results 
(i.e., Killeen, 1968) was relatively brief when compared to the other two studies. Third, the studies that found effects of pacing on schedule value (i.e., Fantino, 1968; the present study) compared both DRL and DRH to an unpaced schedule, while the study that found negative results (i.e., Killeen, 1968) only looked at the effects of a DRO compared to an unpaced schedule.

The three studies all used different methods to produce pacing contingencies. Killeen (1968) used a single, arbitrary value (no responses within $1.5 \mathrm{~s}$ of the last response) while the other two studies used several values. Fantino (1968) used different numbers of required responses in a specific time frame. The present study used a changing criterion design to gradually make response requirements based on the pigeon's baseline performance more stringent. Given the differences seen in the present study in individual IRT requirements $(t>$ $2.57 \mathrm{~s}$ for one pigeon and $t>1.66 \mathrm{~s}$ for the other) a single, non-individualized criterion for all 5 pigeons may not have been strong enough to change the value of the terminal link. As in the case of Pigeon 6893 in the present study, Killeen's results show the value of the terminal-link schedule was unaffected despite control over the terminal-link response rate. Perhaps there is a point where terminal-link behavior is changed but the value of the schedule is not effected until after more stringent constraints are placed on the organism.

Another difference in the studies that found effects of pacing on value was the duration of the studies. Killeen’s (1968) conditions lasted a fixed 17 sessions, while in the present study, in some cases it took upwards of 90 sessions to obtain stable, differentiated responding in the terminal links. Fantino (1968) had conditions that lasted up to 60 sessions. Extended exposure to the contingencies may be an important factor affecting the value of pacing on schedules. Longer exposure to the contingencies may have been required in Killeen's study because the addition of 
the pacing requirements may not be as temporally discriminable on a variable schedule as on a fixed schedule.

The present study and Fantino’s (1968) study compared both DRL and DRH to unpaced schedules, while Killeen (1968) only compared DRO to unpaced schedules. A DRO schedule reinforces non-responding for a certain period of time. An absence of behavior does not give information about what the pigeon is doing, however. It is possible that the pigeon was engaging in some alternative behavior during the 1.5 s period of required non-responding in Killen's study, that might have mitigated any effects of the response requirements that might change value. A DRH or a DRL might be a clearer test of the effects of pacing because it requires a measureable response, not just the absence of a response.

\section{Reinforcement Rates}

Several variables could be responsible for the relatively high value of the unpaced terminal links in the present study. Despite efforts to equate reinforcement rates in the paced and unpaced terminal links there were small but systematic differences seen. The unpaced terminal link consistently had higher reinforcement rates than the paced terminal link and this might explain the value of the unpaced link. Figure 4, however, shows that responding in the initial link was not just matching rates of reinforcement in the terminal links. Small differences in the obtained reinforcement rate were seen across a wide range of choice proportions. It is reasonable to hypothesize that reinforcement rates were not the determining factor in this situation. The best test of this, however, would be a yoked-control condition. In this type of condition, the obtained rates of reinforcement in the paced terminal-link would be used to set the programmed rate of reinforcement in the unpaced terminal link through modification of the VI schedule. This would 
equate the reinforcement rates directly and provide a more convincing demonstration of the independence reinforcement rate and choice seen in this study.

\section{Response Output}

Another factor that may play a role in the value of the unpaced terminal link lies in the speed of responding. Requiring an organism to respond at a higher rate involves a substantial increase in response output when compared to a slower pace. The pigeon could be choosing the schedule that required the lower output. There would be a higher cost-benefit (outputreinforcement) ratio on the lower effort schedule. Preference for the unpaced terminal link was seen under both DRH and DRL conditions, however. The DRL schedule actually required less speed and fewer responses than responding in the unpaced terminal link, so speed or output per se seem like unlikely explanations. The comparisons of DRH and DRL in this study were between- subject comparisons. Within-subject comparisons of DRL and DRH would provide a more convincing demonstration that unpaced schedules are preferred to both DRL and DRH schedules, thus ruling out increased speed and response output as potential explanation for the value of the unpaced terminal link.

\section{Heterogeneous Chains}

In the present study initial and terminal-link schedules differed in the paced conditions but not in the unpaced conditions. The unpaced terminal link was a VI schedule, preceded by similar VI schedule. The paced terminal-link VI had IRT restrictions, while the initial link did not. One possible explanation for the difference in the value of the paced and unpaced schedules is this difference in initial and terminal links. Lattal and Crawford-Godbey (1985) studied the effects of homogenous chains and heterogeneous chains on responding. Homogenous chains consisted of an initial link and terminal link that required the same response topography (key 
pecking). Heterogeneous chains consisted of an initial and terminal link that required different response topographies (key pecking and treadle pressing). Higher initial-link response rates were seen with the homogenous chains when compared to the heterogeneous chains. With chain schedules, the response rate in the initial link is representative of the reinforcing value of the terminal-link schedule. Though response topography and response requirements are not exactly the same, they can be considered analogous.

Starin (1989) conducted a similar study to Lattal and Crawford-Godbey’s (1985) study using concurrent-chains schedules. He investigated the effects of different response topographies in the initial and terminal links. In contrast to the previous study, Starin counter-balanced the initial-link response topography across pigeons. That is, half of the pigeons were required to peck a key in the initial link and half were required to press a treadle. Choices on the initial-link operanda led to either terminal link that required a treadle press or a key peck. Starin found that

pigeons consistently chose the terminal-link schedule associated with keypecking over treadling. This preference occurred regardless of the required topography of the initial link. These findings mitigate the hypothesis that the difference in initial and terminal-link schedules is the primary variable responsible for the differences in preference seen in the present study. Preference for Freedom

Organisms may prefer schedules of reinforcement that have fewer restrictions on the responses that are eligible for reinforcement. In the present study, the paced terminal links involved restrictions on which IRTs were eligible for reinforcement. Paced terminal links were valued less than unpaced schedules. Catania and Sagvolden (1980) investigated the effects of restrictions by studying pigeons’ preference for free and forced choices using a concurrentchains procedure. In their study, initial links led to either a forced-choice terminal link or a free- 
choice terminal link. The forced choice consisted of three lit keys that were associated with extinction and one lit key that was associated with the production of a reinforcer. The free choice consisted of three keys that were associated with the production of a reinforcer and one key that was associated with extinction. Different color stimuli were associated with extinction and reinforcement. In the forced choice, pigeons were restricted to just one key that produced reinforcement while the free choice was free in the sense that the animal got the opportunity to select from several keys that would all produce reinforcement. Pigeons were not constrained to responding on just one key. Free choice was consistently preferred to forced choice.

\section{Behavioral Regulation}

Preference for less restriction may be explained by behavioral regulation. The theory of behavioral regulation conceptualizes behavior as part of a larger system, rather than discrete responses that are strengthened by individual reinforcers, in contrast to most traditional views in behavior analysis (Timberlake, 1993). Behavioral regulation looks more at the system-wide equilibrium of an organism. This system contains three basic parts (Hanson \& Timberlake, 1983). The first part is a stable set point, or state of equilibrium, which is central to the organization of the behavioral system. The second part of this system is a constraint that drives a system away from its set point. The last part of the system is a control function that describes how the system responds to being thrown off its set point. Timberlake discusses how a difference between the current state of the system and the set point affect the output, or behavior of an organism. The difference between the current state and the set point drives the organism and provides motivation for behavior as it attempts to get back in a state of equilibrium.

It is easy to conceptualize the present study in terms of behavioral regulation. If an animal has a natural pace or set point of responding on a schedule, requiring the animal to emit 
responses at a pace other than at that natural pace would throw the system off of its set point. This state of disequilibrium caused by the constraint would be an event to which the system would have to adjust. The state of disequilibrium on the paced terminal link would affect the value of that schedule. Responding that would allow the pigeon to respond at a pace closer to its set point, in this case the unpaced terminal link would be chosen more often.

It is not clear whether a pacing requirement is just not as valuable as an option without a pacing requirement, or if the requirement is aversive. One way to test the aversiveness of pacing requirements is to set up a scenario where the animal can respond to escape the pacing. In this type of experiment, two keys would be available: a response key and an escape key. Responding on the food key would produce reinforcement on a paced schedule. Responding on the escape key would provide a timeout from the session, during which the paced schedule would be suspended. The animal would not be able to earn food reinforcement during the timeout, but it would escape the paced schedule. If the animal was willing to forego periods of earning primary reinforcement to escape the paced schedule there would be evidence that pacing is not only valued less than an unpaced schedule, but that it is aversive.

\section{Pacing and Humans}

In addition to laboratory work with non-human animals, the issue of response pacing in humans has been addressed by the fields of ergonomics and industrial health and safety. Shouskmith (1990) reviewed studies that explored the amount of control a worker has over his or her environment. One of the dimensions investigated was the control over work speed, or pace. Shouskmith found that having more control over work pace was correlated with higher levels of personal satisfaction and adjustment. This study suggests that given a choice, humans might choose unpaced work over paced work. 
A study by Weregeland and Strand (1998) explored the effects of work pace control on the health of pregnant women. They found that pregnancy health improved with increasing power to control work pace, in both manual and non-manual jobs. The risks to the mother's health decreased with increasing control over work pace. Even after adjustment for age, number of prior births, education, smoking, and manual work, the decreasing trend remained significant for pregnancy-induced hypertension (preeclampsia) and low birth weight of the newborn. With the adjustment for manual labor, increased physical strain can not explain the results seen. These data suggest that control of one's pace of responding is related to health. Having to emit responses at a non-self set pace is not preferred and is related to increased physical stress.

Without further investigation it is difficult to speculate what exactly causes the value of a schedule of reinforcement to decrease with the addition of pacing contingencies. What is clear, however, is that in the present study there was a consistent decrease in choice for paced schedules, and hence a decrease in their value. Several studies within and outside of behavior analysis support the idea that schedules of reinforcement that are less restrictive are preferred to those that are more restrictive. 


\section{References}

Catania, A., \& Sagvolden, T. (1980). Preference for free choice over forced choice in pigeons. Journal of the Experimental Analysis of Behavior, 34(1), 77-86.

Fantino, E. (1968). Effects of required rates of responding upon choice. Journal of the Experimental Analysis of Behavior, 11, 15-22.

Ferster, C.B, \& Skinner, B.F. Schedules of reinforcement. New York: Appleton-Century-Crofts, 1957.

Fleshler, M., \& Hoffman, H. (1962). A progression for generating variable-interval schedules. Journal of the Experimental Analysis of Behavior, 5(4), 529-530.

Killeen, P. (1968). Response rate as a factor in choice. Psychonomic Science, 12, 34.

Lattal, K., \& Crawford-Godbey, C. (1985). Homogeneous chains, heterogeneous chains, and delay of reinforcement. Journal of the Experimental Analysis of Behavior, 44(3), 337342.

Lattal, K. (1991). Scheduling positive reinforcers. In I. Iversen and K. Lattal (Eds.), Experimental analysis of behavior, Parts 1 \& 2 (pp. 87-134). New York, NY US: Elsevier Science.

Moore, J., \& Fantino, E. (1975). Choice and response contingencies. Journal of the Experimental Analysis of Behavior, 23, 339-347.

Onwuegbuzie, A., \& Seaman, M. (1995). The effect of time constraints and statistics test anxiety on test performance in a statistics course. Journal of Experimental Education, 63, 115124.

Premack, D. (1962). Reversibility of the reinforcement relation. Science, 136, 255-257. 
Preston, R., \& Fantino, E. (1991, March). Conditioned reinforcement value and choice. Journal of the Experimental Analysis of Behavior, 55(2), 155-175.

Shouksmith, G. (1990). Job control, paced tasks, and discretion. Perceptual and Motor Skills, 71(2), 409-410.

Starin, S. (1989, March). Choice and terminal-link response topography. Journal of the Experimental Analysis of Behavior, 51(2), 243-257.

Stubbs, D., \& Pliskoff, S. (1969). Concurrent responding with fixed relative rate of reinforcement. Journal of the Experimental Analysis of Behavior, 12(6), 887-895.

Thomas, W. (2007). Effects of "fast" and "slow" pacing contingencies on the value of a schedule of reinforcement. Unpublished honor's thesis. West Virginia University, Morgantown, WV.

Wergeland, E., \& Strand, K. (1998). Work pace control and pregnancy health in a populationbased sample of employed women in Norway. Scandinavian Journal of Work, Environment \& Health, 24(3), 206-212. 